\title{
ANALYSIS ON THE DYNAMIC CHANGES IN A REGIONAL ECOSYSTEM AND EVALUATION OF ITS SERVICE VALUES BASED ON REMOTE SENSING
}

\author{
Shi-dong Wang ${ }^{\mathrm{a}, \mathrm{b}}$, He-bing Zhang ${ }^{\mathrm{a}}$, Xin-chuang Wang ${ }^{\mathrm{a}}$ \\ ${ }^{a}$ School of Surveying and Land Information Engineering, Henan Polytechnic University, Jiaozuo 454000, China \\ (wsd0908@163.com) \\ b Jiangsu Key Laboratory of Resources and Environmental Information Engineering, Xuzhou 221116, China
}

KEY WORDS: Remote sensing, ecosystem service values, evaluation, dynamic change

\begin{abstract}
:
The ecosystem service value is an important concept and an index that reflects the quality of the regional ecological environment status and the measurement of the total ecological benefits. In this study, based on the characteristics of land use and the types of ecosystem in the studied area, the ecological indicators including the net primary productivity of the vegetation and the vegetation cover were selected. Landsat TM remote sensing image, ground-based observation, meteorological data and statistical data etc. were applied to establish the remote sensing-based assessment criteria and assessment model for quantitative estimation of the ecosystem service value. The established assessment criteria and model were applied to conduct the quantitative calculation on the value of the single ecosystem service and the ecosystem service value per unit area. The results indicated that during the decade of 2000-2010, with the inter-conversion of different types of land use, the total value of the ecological service in the studied area displayed a gradually decreasing trend. Among which, the values of ecological service of the cultivation land, wetland and the total ecological service were reduced by $11.92,11.75$ and $5.74 \%$, respectively. While the values of ecological services of forest land, waters and intertidal zone were increased to certain extend. However, these increased values did not change the continuously decreasing trend of the total value of ecosystem service in the studied area. Based on these assessments, the spatially- and temporally-changing patterns of the values of ecosystem service in the studied area were analysed to reveal their intrinsic relationship between the land use and the changes in values of ecosystem service.
\end{abstract}

\section{INTRODUCTION}

Ecosystem service refers to the important benefits arising from the naturally functioning ecosystem and its compositions for supporting the survival and development of human beings ${ }^{[1]}$. The functions of ecosystem services include all the natural resources and ecological environment that provide human beings with services and benefits. The service values of ecosystem are expressed in several forms including not only the material resources with physical forms and direct values, such as raw materials, food, medicines, mineral resources and water resources etc., but also the non-material resources without physical forms but with indirect values, such as conservation of water and soil, water resources conservation, climate regulation and landscape enjoyment ${ }^{[2]}$.

The value of ecosystem service is an important concept and an index that reflects the quality of the regional ecological environment status and the measurement of the total ecological benefits. In this study, we applied remote-sensing image to conduct the quantitative measurement of the service value of the regional ecosystem. category is the services with direct value, the products of ecosystem, i.e. the ecosystem provides human beings with raw materials, food, and medicines etc., which have the direct commercialization functions; and the second category is the service with indirect values, i.e. the environment that support and maintain the survival and development of human beings, such as the functions of ecosystem on reservation of water resources, regulation of climate, conservation of soil and water, renew and maintenance of soil fertility and cycle of nutrients etc., which hardly have the direct commercialization functions ${ }^{[1,2]}$. While the indirect values are generally not expressed in the budge system in a majority of countries, it values may be far more than the direct values ${ }^{[1]}$.

In this study, from the perspective of macro-ecology and based on the characteristics of the estimated service values of the ecosystem in the remote-sensed region, we defined the evaluation indexes of services value of ecosystem through using the remote sensing technique. These evaluation indexes were listed in Table 1.

Table 1 Evaluation index of ecosystem services value based on remote sensing technology

Ecosystem service function $\quad$ Value embodiment

$\frac{\text { Ecosystem service function }}{\text { Food production and solar energy fixation }}$

2.1 Assessment indexes for the service values of ecosystem based on remote-sensing imaging

The ecosystem service functions refer to the natural environmental conditions and eco-efficiency formed by iimulation of nutrient element cycling

Water supply and water regulation

Conservation of sediment and control of erosion

Climate regulation ecosystem and the ecological process to maintain the survival rovide the site for living and reproduction of and development of human beings ${ }^{[1,3]}$. The ecosystem servicorganisms; control of the quantity of harmful functions are generally divided into two categories: the first organisms
Production of organic substance

Nutrient element cycling and storage

Water resource conservation

Conservation of water and soil

$\mathrm{CO}_{2}$ Absorption and release of $\mathrm{O}_{2}$ 


\subsection{Remote-sensing classification of ecosystems}

Different types of ecosystems have different proportions of the direct and indirect values. Thus, the most important task for the measurement of the service values of ecosystem based on remote sensing technique is to establish a classification system for ecosystems that is suitable to be used in measurement of the service values of ecosystem by using remote-sensing technique and then, to learn the spatial distribution patterns of these ecosystems by using multiple-source and multiple-scale remote sensing technique and methods ${ }^{[1]}$.

Based on "Current Land Use Condition Classification for National Standard of the People's Republic of China" (National Standards of People's Republic of China GB/T21010 - 2007) and The National Land Use and Land Cover Classification System of People's Republic of China" and referenced the characteristics of land use in the studied region and the spatial resolution $(30 \mathrm{mx} 30 \mathrm{~m})$ of TM remote-sensing image ${ }^{[2]}$, in this study, six types of land-use were classified and they are cultivation land, forest land, construction-used land, wetland, waters and intertidal land.

\subsection{Remote-sensing measurement of ecological indexes}

For the same ecosystems, when they are distributed in different spatial locations, their quality statuses are quite different and are continuously changed with time. Furthermore, the values of ecosystem service are also continuously changed with the changes in the quality statuses of ecosystems ${ }^{[1,4]}$. The quality status of ecosystems can be reflected by a series of ecological indexes. The full cover data for the temporal- and spatialchanges in these ecological indexes can be obtained only with remote-sensing method ${ }^{[1,4]}$. According to the characteristics of the studied region, in this study, we selected two ecological indexes, i.e. the net primary productivity (NPP) of vegetation and the vegetation cover, to reflect the quality status of the ecosystem.

(1) The net primary productivity of vegetation

The primary productivity of vegetation, also known as net primary productivity (NPP), refers to the quantity of organic substance produced by green plants in per unit time and in per unit area, which is expressed by the organic carbon fixed via plant photosynthesis minus the fraction of carbon consumed by plant's respiration ${ }^{[1,4]}$. In this study, by using remote-sensing technique, the NPP of vegetation was calculated by using Carnegie-Ames-Stanford Approach based on the view of point of resource balance.

(2)The vegetation cover

The vegetation cover (f) refers the proportion of the projected area of vegetation in relative to per unit area, which reflects degree of vegetation density and the size of plant photosynthetic area and is related to vegetation index. The vegetation cover (f) can be obtained via normalized difference vegetation index (NDVI).

\subsection{Remote-sensing quantitative measurement model for values of ecosystem service}

The total values of ecosystem service in certain region is the sum of both the direct and the indirect values contributed by various ecosystems within that region, which are changed with time and with the differences in the types, areas and qualities of various ecosystems within that region ${ }^{[5-8]}$. The total values (V) of ecosystem service within certain region can be expressed with equation (3-1) as follows:

$$
V=\sum_{c=1}^{n} V_{c}
$$

Where $c=1,2, \ldots, n$, is the type of ecosystem; $V_{c}$ is the value of ecosystem service of the $\mathrm{C}^{\text {th }}$-type ecosystem:

$$
V_{c}=\sum_{i=1}^{n} \sum_{j=1}^{m} R_{i j} \times V_{c i} \times S_{i j}
$$

Where $\mathrm{i}=1,2, \ldots, \mathrm{n}$, is the $\boldsymbol{i}^{\text {th }}$ ecosystem service function of the $\mathrm{C}$-type ecosystem; $\mathrm{V}_{\text {ci }}$ represents the values ecosystem service values per unit area of the $i^{\text {th }}$ ecosystem service type; $\mathrm{j}=1,2, \ldots$, $\mathrm{m}$, was the spatial number of pixel of $\mathrm{V}_{\mathrm{ci}}$ in certain region, $\mathrm{S}_{\mathrm{ij}}$ is the size of pixel area (in this study, this area was set as $30 \mathrm{~m}$ $\mathrm{x} 30 \mathrm{~m}) ; \mathrm{R}_{\mathrm{ij}}$ was the adjustment coefficient of pixel, which is determined by the quality status of ecosystem ${ }^{[1]}$.

$$
R_{i j}=F\left(A_{1}, A_{2}, \ldots, A_{n}\right)
$$

Where $\mathrm{A}_{1}, \mathrm{~A}_{2}, \ldots, \mathrm{A}_{\mathrm{n}}$ is the ecological indexes reflecting the quality status of ecosystem; $V_{c i}$ values for the same type of ecosystem under different quality status are different and their differences can be adjusted via $\mathrm{R}_{\mathrm{ij}}{ }^{[1]}$. In this study, we selected NPP of vegetation and the vegetation cover $\left(f_{j}\right)$ as the ecological indexes to describe the quality status of ecosystem at that year ${ }^{[4]}$. For a particular pixel, the adjustment coefficient $R_{i j}$ can be expressed by the following equation:

$$
R_{i j}=\left(\frac{N P P_{j}}{N P P_{\text {mean }}}+\frac{f_{j}}{f_{\text {mean }}}\right) / 2
$$

Where $N P P_{\text {mean }}$ and $f_{\text {mean }}$ are the mean values of $N P P$ and $f$ of the $\mathrm{C}^{\text {th }}$-type of ecosystem in certain region while $N P P_{j}$ and $f_{j}$ are the pixels of the values of $N P P$ and $f^{[4,5]}$.

The net primary productivity $(N P P)$ of vegetation was calculated with the modified solar energy utilization efficient model and the detail method for calculation would be given below.

The vegetation cover $(f v)$ refers the proportion of projection area of vegetation in relative to per unit area, which is used to measure the quantity of the vegetation on the ground surface. There is a relationship between normalized difference vegetation index (NDVI) data for each pixel and $f_{v}$ as follows:

$$
N D V I_{i}=\sum_{j=1}^{Q} N D V I_{i j} f_{j}+e_{i}
$$

Where NDVIi is the NDVI data at the $i^{\text {th }}$ month; $N D V I_{i j}$ is the value of the $\mathrm{j}^{\text {th }}$ type of vegetation cover at the $i^{t h}$ month; $\mathrm{f}_{\mathrm{j}}$ is the proportion of the $\mathrm{j}^{\text {th }}$ type of vegetation cover in relative to pixel; $\mathrm{e}_{\mathrm{i}}$ is errors. The restriction condition for this model is as follows:

$$
\sum_{j=1}^{Q} f_{j}=1
$$

Considering the practical application of this model, based on the linear mixed model hypothesis, the NDVI for each pixel can be thought to be consisted of the sum of the fraction of vegetation cover $\left(f_{v}\right)$ and the fraction of the exposed soil $\left(1-f_{v}\right)$, i.e.:

$$
N D V I=N D V I_{V} f_{v}+N D V I_{S}\left(1-f_{v}\right)
$$

Where $N D V I_{v}$ is the NDVI value of the part of vegetation cover, $N D V I_{s}$ is the NDVI value of the part of exposed soil. The annual maximal NDVI can reflect better the vegetation cover in the ground-based surface in the season when vegetation grows best. In the actual calculation, the maximal NDVI value was selected to replace $N D V I_{v}$ while the minimal value of NDVI was selected to replace $N D V I_{s}$, then the calculation equation (8) for vegetation cover can be expressed as follows:

$$
f_{v}=\frac{N D V I-N D V I_{\min }}{N D V I_{\max }-N D V I_{\min }}
$$


According to the requirement for the calculation of the ecological service value in the studied area, the remote sensing model for the evaluation of the ecological service values mainly included three parts: 1) the remote-sensing classification of ecosystems; 2) remote sensing measurement of ecological indexes; and 3) the calculation of ecological service values of the values of single ecosystem and the values of ecological service per unit area ${ }^{[9-13]}$.

\section{THE STUDIED AREA}

\subsection{General information about the studied region}

Dawa county, which was selected as the studied area, is located in southwest of Liaoning Province, and the north edge of Liaodong Bay. Its south and north are surrounded by Daliao River. Its west faces the Bohai Sea and Liaodong Bay. Geologically, this county is located between $121^{\circ} 48^{\prime}$ E-122

$21^{\prime} \mathrm{E}$ and $40^{\circ} 41^{\prime} \mathrm{N}-41^{\circ} 09^{\prime} \mathrm{N}$ and displays the typical characteristics of the coastal ecology. The total land area of the entire area is $1387 \mathrm{~km} 2$. The topography of this county is flat with a plenty of low-lying water. This is a coastal plain formed and developed by the deposits of in tidal flats from DaLiao Rive and Liao River. The climate in this entire area belongs to humid temperate continental monsoon climate. The mean annual atmospheric temperature is $9.3 \mathrm{oC}$ and the extremely high temperature is $32.7 \mathrm{oC}$ and the extremely low temperature is 23oC. The mean annual precipitation is $647.3 \mathrm{~mm}$. There is abundant water resource. DaLiao River, Liao River, Xinkai River and Shuangtaizi River all flow through this area. The soils in this area include mainly rice soil, meadow soil and bog soil. The land-use efficiency is relatively high.

\subsection{The original data sources and data treatment}

The original data used in this study were mainly the Landsat TM remote-sensing images taken in the years of 2000, 2005 and 2010. In addition, the original data also included the soil, vegetation, climate and statistical data in the studied area. Among which, TM remote-sensing images taken in three time points, i.e. September 3, 2000, August 22, 2005, and September 20,2010 , were selected to conduct geometric rectification and registration based on the land use status map in 1:10000 magnification. The image mosaic and cropping were conducted within ENVI4.7. The images were classified by using the nonsupervise classification method as the primary method with visual interpretation as the supplement. Finally, several sampling areas were randomly selected according to the groundbased data and field survey results. Their classification confusion matrix and Kappa coefficient were calculated. The results showed that the overall accuracy of land use classification was $87.4 \%$ and Kappa coefficient was 0.81, indicating that the results are good. The other data were treated with the corresponding digitalization and standardization.

\section{RESULTS AND ANALYSIS}

\subsection{Analysis on the quantitative changes in the values of ecosystem service}

Based on the quantitative remote-sensing measurement method for the values of ecosystem service described above, under ArcGIS software environment, the service values of various ecosystems within the studied area in the years of 2000, 2005 and 2010 were calculated. The results were presented in Table 2.

It can be seen from Table 2 that the total values of ecosystem service in the studied area from 2000-2005 was reduced from 959 million Yuan/a in 2000 to 942 million Yuan/a in 2005, which was reduced by $1.75 \%$. Among which, the reduction in cultivation land-use area and wetland-use area was more obvious. The cultivation land-use area was reduced by $7.02 \%$ while the wetland land-use area was reduced by $3.22 \%$. The reduction in value of ecological service of the cultivation-use land was mainly due to the reason that during the recent years the rapid social and economic development in the studied area led to the continuing occupancy of the construction-used land on the cultivation land, making the area of cultivation land use substantially reduced. Additionally, the changes in natural environment and the disturbance of human factors also led to the continuing reduction of the area wetland land use. These are all the main reasons for the reduction in the values of ecological service. During the period of 2000-2005, the values of forest ecosystem service was increased by $24.00 \%$ and the s values of waters ecosystem service was increased by $13.12 \%$ and the values of intertidal-ecosystem service was increased by $3.23 \%$. The increases in the service values of these three types of ecosystems were mainly due to the increase in areas of their land use. The increase in the area forest land use was due to the reason that during the recent years, the government in studied area launched the construction of "ecological county" and the people continued afforestation and forestation, making the area of forest land use continuously increased. The increase in the area of waters was due to the reason that aquaculture industry was continuously developed in the studied area, making the area of water surface for aquaculture continuously increased. While the service values of forest land, waters and intertidal ecosystems were increased during the period of 2000-2005, because their proportions in relative to the total values of ecosystems were relatively smaller, the increases in the service values of these three types of ecosystems did not change the continuously decreasing trend in the total values of ecological service in the studied area.

During the period of 2005-2010, the mean annual total values of ecological service was reduced from 942 million Yuan/a in 2005 to 904 million Yaun/a in 2010, which was reduced by $4.05 \%$. Among which, the service values of cultivation land, forest land; wetland and intertidal area were reduced by 5.27 , $19.22,8.82$ and $0.76 \%$, respectively. The decrease in the values of ecological service was mainly due to the reason that the area of cultivation land, the major contributor to the ecological service values, was continuously reduced. The decrease in the area of cultivation land was mainly due to the reason that the construction-used land continuously occupied the cultivation land. The substantial reduction in the area of forest land was due to the reason that during the recent years, the constructionused land in both urban and rural areas was continuously expanded and the implement of continuous demolish and merge of the villages in rural areas. The reduction in wetland and intertidal-flat areas was the results of the combined actions of both natural and human factors. These are the major reasons for the reduction in total values of the ecosystem service in the studied area. During 2000-2005, only the value of water ecosystem service was increased by $9.13 \%$, mainly due to the reason that aquaculture industry was continuously developed in the studied area, making the area of water surface for aquaculture continuously increased. Generally, during the period of 2005-2010, the total values ecosystem service values in the studied region were continuously reduced and the 
reduction rate in this period was far more than that in the period of 2000-2005.

After combining the changes in the values of ecosystem service in the studied area during the period of 2000-2010, it can be seen that during this decade, with the inter-conversion of the types of land-use, the total value of ecological service displayed a gradually decreasing trend. Among which, the values of ecological service of cultivation land and wetland ecosystem were reduced by 11.92 and $11.75 \%$, respectively. The total value of ecosystem service was reduced by $5.74 \%$. Although the values of forest, waters and intertidal ecosystem were increased to certain extend, they did not change the continuously decreasing trend in the total values of ecosystem service in the studied area.

\begin{tabular}{|c|c|c|c|c|c|c|c|c|c|}
\hline & & 2000 & & 2005 & & 2010 & & & \\
\hline $\begin{array}{l}\text { Type of } \\
\text { Land-use }\end{array}$ & $\begin{array}{c}\text { Eco } \\
\text { syst } \\
\text { em } \\
\text { Ser } \\
\text { vice } \\
\text { val } \\
\text { ues }\end{array}$ & $\begin{array}{c}\text { Proporti } \\
\text { on } \\
(\%)\end{array}$ & $\begin{array}{c}\text { Val } \\
\text { ues } \\
\text { of } \\
\text { Eco } \\
\text { syst } \\
\text { em } \\
\text { serv } \\
\text { ice } \\
\end{array}$ & $\begin{array}{c}\text { Proporti } \\
\text { on } \\
(\%)\end{array}$ & $\begin{array}{c}\text { Val } \\
\text { ues } \\
\text { of } \\
\text { eco } \\
\text { syst } \\
\text { em } \\
\text { serv } \\
\text { ice }\end{array}$ & $\begin{array}{l}\text { Propor } \\
\text { tion } \\
(\% \\
)^{2}\end{array}$ & $\begin{array}{l}\text { Chang } \\
\text { e rate } \\
\text { during } \\
2000- \\
2005 \\
(\%)\end{array}$ & $\begin{array}{c}\text { Chang } \\
\text { e rate } \\
\text { during } \\
2005- \\
2010 \\
(\%)\end{array}$ & $\begin{array}{c}\text { Chang } \\
\text { e rate } \\
\text { during } \\
2000- \\
2010 \\
(\%)\end{array}$ \\
\hline $\begin{array}{c}\text { Cultivation } \\
\text { land }\end{array}$ & $\begin{array}{c}4.9 \\
3\end{array}$ & 51.42 & $\begin{array}{c}4.5 \\
9\end{array}$ & 48.67 & $\begin{array}{c}4.3 \\
4\end{array}$ & 48.05 & -7.02 & -5.27 & -11.92 \\
\hline Forest land & $\begin{array}{c}0.2 \\
7\end{array}$ & 2.83 & $\begin{array}{c}0.3 \\
4\end{array}$ & 3.57 & $\begin{array}{c}0.2 \\
7\end{array}$ & 3.01 & 24.00 & -19.22 & 0.17 \\
\hline Waters & $\begin{array}{c}0.8 \\
8\end{array}$ & 9.21 & $\begin{array}{c}1.0 \\
0\end{array}$ & 10.61 & $\begin{array}{c}1.0 \\
9\end{array}$ & 12.07 & 13.12 & 9.13 & 23.45 \\
\hline Wetland & $\begin{array}{c}1.8 \\
0\end{array}$ & 18.79 & $\begin{array}{c}1.7 \\
4\end{array}$ & 18.51 & $\begin{array}{c}1.5 \\
9\end{array}$ & 17.59 & -3.22 & -8.82 & -11.75 \\
\hline $\begin{array}{l}\text { Intertidal } \\
\text { area }\end{array}$ & $\begin{array}{c}1.7 \\
0\end{array}$ & 17.75 & $\begin{array}{c}1.7 \\
6\end{array}$ & 18.65 & $\begin{array}{c}1.7 \\
4\end{array}$ & 19.29 & 3.23 & -0.76 & 2.44 \\
\hline $\begin{array}{l}\text { Construction } \\
\text { used land }\end{array}$ & $\begin{array}{c}0.0 \\
0\end{array}$ & 0.00 & $\begin{array}{c}0.0 \\
0\end{array}$ & 0.00 & $\begin{array}{c}0.0 \\
0\end{array}$ & 0.00 & 0.00 & 0.00 & 0.00 \\
\hline Total & $\begin{array}{c}9.5 \\
9 \\
\end{array}$ & 100.00 & $\begin{array}{c}9.4 \\
2 \\
\end{array}$ & 100.00 & $\begin{array}{c}9.0 \\
4 \\
\end{array}$ & $\begin{array}{c}100.0 \\
0\end{array}$ & -1.75 & -4.05 & -5.74 \\
\hline
\end{tabular}

\subsection{Analysis on the changes in the spatial patterns of ecological service values}

According to the measurement method for ecological service values based on remote sensing described above. Under the ArcGIS software environment, the map of ecosystem services value at years 2000, 2005 and 2010 year in the studied area (Figure 1) was obtained.

It can be seen from the map of values of ecosystem services at three time points that the characteristics of the spatial differentiation of values the ecological service basically displayed a gradually decreasing trend from the southwest coast toward to northeast inland. It can be seen from the map that a large piece of wetland makes important contribution to the values of ecosystem service. The mean ecological service value per unit area in three years was 10640 yuan/ hm2. Its value of ecological service per unit area was only second to that of forest land but the total value of ecological service was only second to that of cultivation land and was ranked the second place, followed by that of intertidal area in the southwest coast, which also made an important contribution to the service functions of ecosystem. In addition, waters, which plays important role in the service functions of ecosystem, is also distributed in the west coastal zoon. For instance, the delta reservoir and Rongxin reservoir are also located in the west. Therefore, the values of ecological service in the west were significantly higher than those in the east. Furthermore, it can also be seen from the characteristics of the spatial distribution of values of ecological service during three time points that the total values of ecological service of cultivation land per unit area, which was ranked the first place of total values of ecological service in term of the values of single ecosystem service, also displayed a gradually decreasing trend from the southwest toward northeast. These changing trends of values of ecological service are basically in agreement with the distribution map of the mean annual temperature and mean annual rainfall. Therefore, it can be concluded that the effects of temperature and rainfall on the changes in values of ecological service are quite significant. In the areas nearby the coast, the atmosphere temperature and rainfall are more suitable of the vegetation growth. Thus, the values of ecological service in the studied area displayed a gradually decreasing trend from the southwest coast toward the northeast inland. This distribution trend is similar to the spatial distribution pattern of the vegetation cover and NPP of vegetation. Additionally, in can be seen from the spatial distribution map of value of ecological service in three years of 2000, 2005 and 2010 that the values of ecological service per unit area of various types of land-use in 2005 was slightly higher than those in 2000 and 2010. This is mainly due to the reason that in the year of 2005 the mean annual temperature was on the high side and the mean annual rainfall was higher as compared to those in years of 2000 and 2010. The change in water temperature directly affects the changes in the values of ecological service.

In general, during the period from 2000 to 2010, the distribution patterns of ecological service values in the studied area were not changed largely. The spatial distribution structure and patterns were relatively stable. There were obvious boundaries among the values of ecological service of various types of land-use. The total values of ecological service displayed a gradually decreasing trend from the southwest coast toward the northwest inland.

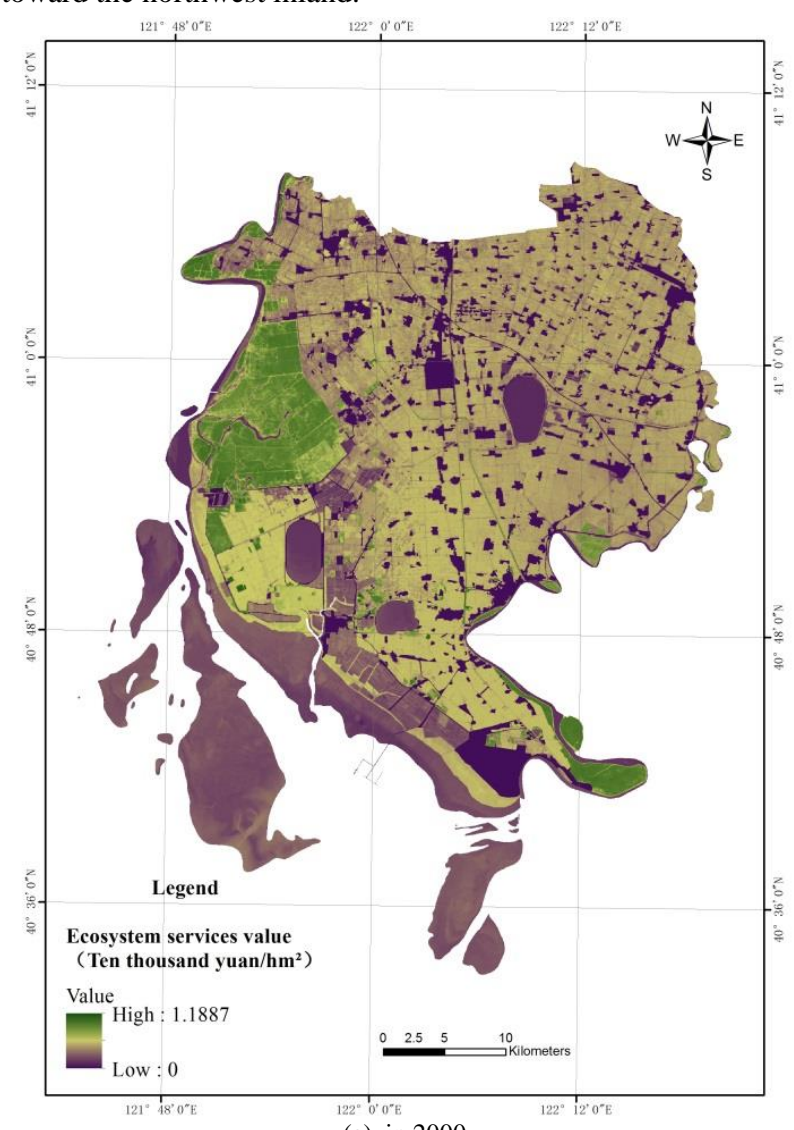

(a) in 2000 

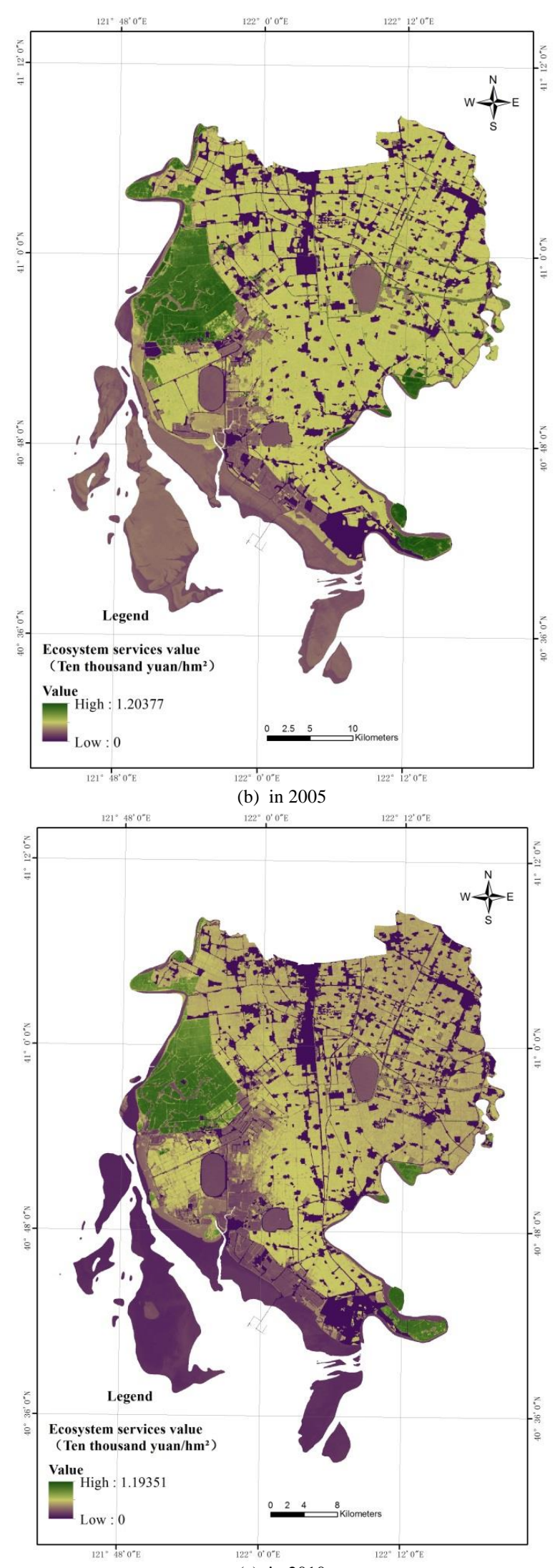

(c) in 2010

Fig. 1 Map of the value of ecosystem services at years 2000, 2005 and 2010 in the study area

\subsection{Analysis on the correlation between ecological services and the changes in land-use}

Table 2 presented the comparative analyses on the correlation between the values of ecological service and the changes in land-use in the studied area. It can be seen from Table 2 that in the recent decade, while the total area of land use in the studied area was not changed, the total values of ecological service were continuously decreased. The main reason for this decrease is that the types of ecological land-use that make the major contributions to the values of ecological service were continuously decreased whereas the construction-used land that does not have any values of ecological service was continuously increased, finally leading to the continuous decrease in the total values of ecological service in this region. Additionally, the changes in values of single ecosystem service of various types of land-use displayed certain positive correlation with changes in their corresponding areas. For instance, in the three years of 2000, 2005 and 2010, the proportions of cultivated lane area were $51.59,46.96$ and $45.25 \%$ and the proportions of the values of their ecological service were 51.42, 48.67 and $48.05 \%$, respectively; the proportions of forest-land area were $1.65,2.02$ and $1.64 \%$, respectively and the proportions of their ecological service values were $2.83,3.57$ and $3.01 \%$, respectively; the proportions of waters area were $9.82,13.23$, and $15.69 \%$ and the proportions of their ecological service values were 9.21, 10.61 and $12.07 \%$, respectively; the proportions of wetland area were $8.34,9.41$, and $10.30 \%$ while the proportions of their ecological service values were $18.79,18.51$ and $17.59 \%$, respectively; the proportions of tidal-flat area were 12.46, 1.77 , and $10.60 \%$ while the proportions of their ecological service values were $17.75,18.65$ and $19.29 \%$, respectively. Although the proportions of construction-used land were quite large, its values of ecological service were zero.

It can be seen from the comparative analysis on the correlations between the values of ecological service and the changes in the types of land-use in the studied area described above that while the values of a single ecosystem service displayed certain positive correlations with the area of the type of land-use, the types of land-use with higher values of ecological service per unit area accounted for lower proportions of total areas of landuse but higher proportions of the total values of ecological service. For instance, in the three years of 2000, 2005 and 2010, wetland area accounted for $9.35 \%$ of total area of land use while the proportion of its values of ecological service account for $18.30 \%$ of the total values of ecological service. The areas of forest land and intertidal area accounted lower proportions of total areas of land-use while the values of their ecological service accounted relatively larger proportions of total values of ecological service. These results indicate that in order to build a better ecological environment and to obtain greater ecological benefits, the types of land-use that have important functions in ecological service with lower proportions of areas of land-use, such as wetland, forest land, waters and intertidal area, should be included within the ecologically protected regions. The spatial distribution patterns should be properly laid out. This will maximally avoid the occurrence of regional ecological and environmental problems at certain level of ecological safety.

\section{CONCLUSIONS}

In this study, based on the characteristics of land-use and types of ecosystems in the studied region, we selected two ecological indexes, i.e. net primary productivity (NPP) of vegetation and vegetation cover and applied Landsat TM remote-sensing image, ground-based observation, meteorological data and 
statistical data etc. to establish the remote sensing-based assessment criteria and an assessment model for quantitative measurement of the value of ecosystem service. Using this system, we quantitatively calculate the values of single ecosystem service and the values of ecosystem service per unit area in the studied region. On this basis, we analysed the temporally and spatially changing patterns of the values of ecosystem service in this studied region and examined the correlations between the changes in the types of land-use and the changes in the values of ecosystem service. The results obtained from this study are of importance and significance for elucidating the mechanisms of ecological safety, promoting the regional environmental construction and the substantial social and economic development in the studied area.

\section{ACKNOWLEDGEMENTS (OPTIONAL)}

This research was supported by National Natural Science Foundation of China (No. 41301617, 41401500), Key Science and Technology Projects of Henan Province (No. 142102310033), China Coal Industry Association Guidance Program (No. MTKJ-2013-310), Scientific Research Foundation for Jiangsu Key Laboratory of Resources and Environmental Information Engineering (No. JS201306), Dr. Fund of Henan Polytechnic University (B2014-016), Technological Innovation Team of Henan University Support Program (13IRTSTHN029).We also want to express our respect and thanks to the anonymous reviewers and the editors for their helpful comments in improving the quality of this paper.

\section{REFERENCES}

[1] Li J, Chen Y-H, Pan Y-Z, et al.. Studies on Technology System of Ecological Property Measurement Based on Remote Sensing Technology in Western China [J]. Sensing letter. 2003(3): 8-12.

[2] Gao Q. Land Use Security Pattern for Farming-pastoral Zone of North China, a Case Study at Changchuan Watershed [D]. Beijing Normal University, 2003.

[3] Zhao R, Huang A, Qin Z, et al. Farmland and other ecosystem services research and evaluation methods [J]. Agricultural Systems Science and Comprehensive Study. 2003, 19(4): 267-270.

[4] Miao Z. The evaluation of ecological assets in Jilin by the quantitative method of remote sensing [D]. Northeast Normal University, 2010.

[5] Rocco S, Elisa M, Riccardo S. Delphi-based change assessment in ecosystem service values to support strategic spatial planning in Italian landscapes[J]. Ecological Indicators. 2011, 7(19): 939-950.

[6] Running S W, Thornton P E, Nemani R, et al. Global terrestrial gross and net primary productivity from the earth observing system[M]. New York: Springer-Verlag, 2000.

[7] Kabrick J M, Zenner E K, Dey D C, et al. Using ecological land types to examine landscape-scale oak regeneration dynamics[J]. Forest Ecology and Management. 2008(255): 3051-3062.

[8] Bjorklund J, Limburg K, Rydberg T. Impact of production intensity on the ability of the agricultural landscape to generate ecosystem services: An example from Sweden[J]. Ecological Economics. 1999(29): 269-291.

[9] Holmund C, Hammer M. Ecosystem services generated by fish populations[J]. Ecological Economics. 1999(29): 253-268.
[10] VAN Vuren D P, Smets E M W. Analysis ecology footprints of Benin, Bhutan, Costa Rica and the Netherlands[J]. Ecological Economies. 2000, 34(234): 115-130.

[11] Richard B, Howarth R, Farber S. Accounting for the value of ecosystem services[J]. Ecological Economics. 2002, 41(3): 421-429.

[12] W Luck G, C Daily G, Paul R E. Population diversity and ecosystem services [J]. Trends in Ecology \& Evolution. 2003, 18(7): 331-336.

[13] Penelope L, Fabien Q, Sandra L. The diversity of the ecosystem services concept and its implications for their assessment and management [J]. Comptes Rendus Biologies. 2011(334): 441-449. 